\title{
DO FENÔMENO PSICOSSOMÁTICO AO SINTOMA: A ADERÊNCIA DO SUJEITO AO DIAGNÓSTICO MÉDICO E O TRABALHO ANALİTICO*
}

Doris Rinaldi, Roseane Freitas Nicolau e Claudia Escórcio Gurgel do Amaral Pitanga

\author{
Doris Rinaldi \\ Professora adjunta \\ do Instituto de \\ Psicologia da Uerj, \\ atuando no Programa \\ de Pós-graduação \\ em Psicanálise, \\ procientista/Uerj, \\ pesquisadora do \\ CNPQ, doutora \\ em Antropologia \\ Social/Museu \\ Nacional/UFRJ, \\ psicanalista, membro \\ de Intersecção \\ Psicanalítica do \\ Brasil.
}

Roseane Freitas Nicolau Professora adjunta da Universidade Federal do Pará, atuando na graduação e na Pós-Graduação em Psicologia, doutora em Sociologia (UFC/ EHESS), psicanalista, psicóloga, membro da Escola Letra Freudiana.

Claudia Escórcio Gurgel do Amaral Pitanga Doutoranda do Programa de Pós-Graduação em Psicanálise da Uerj, mestre em Pesquisa e Clínica Psicanalítica pela Uerj, supervisora do Setor de Psicologia Geral da Associação Fluminense de Reabilitação, psicóloga, psicanalista.
RESUMO: Discute-se a prática psicanalítica com sujeitos que apresentam fenômenos psicossomáticos, por meio de duas experiências de análise: a primeira, realizada em uma clínica-escola, e a outra em uma instituição médica de reabilitação motora. Os casos apresentados permitiram refletir sobre as possibilidades de reposicionamento do sujeito na relação com o seu próprio corpo, pois evidenciam a passagem de uma posição subjetiva — marcada pela aderência ao diagnóstico médico — a outra posição, por meio da formação de um sintoma no sentido analítico, no qual o sujeito pode se reconhecer.

Palavras-chave: Psicossomática, holófrase, sintoma e gozo.

ABSTRACT: From the psychosomatic phenomenon to the symptom: the adherence. This work aims to discuss the psychoanalytic practice applied to subjects that present psychosomatic phenomena, by means of two different analytical experiments: one of them taking place in a training clinic, and the other one in a medical institution for motor rehabilitation. The cases presented here enabled a reflection over the possibilities of repositioning of the subject in the relation with her/his own body, as they highlight the transition from a subjective position, marked by an adherence to the medical diagnosis, to another one in which the subject recognizes herself/himself by means of the formation of a symptom in the analytical sense.

Keywords: Psychosomatics, holophrase, symptom and joyment.

\footnotetext{
* Este artigo é resultado da pesquisa clínica que se realiza no âmbito do Grupo de Trabalho "Dispositivos Clínicos em Saúde Mental”, coordenado pela professora Andréa Guerra, da Associação Nacional de Pesquisa e Pós-Graduação em Psicologia (Anpepp). Suas autoras, duas docentes e uma doutoranda, participaram deste grupo, que integra pesquisadores de diversas universidades do país.
} 
$\mathrm{N}$ este trabalho, discutiremos a prática psicanalítica com sujeitos que evidenciam de maneira exemplar o hiato estabelecido pelo progresso da ciência sobre a relação da medicina com o corpo, nomeado por Lacan como "falha epistemossomática” (LACAN, 1966/2001), e as possibilidades de reposicionamento destes na relação com seus próprios corpos, a partir de experiências de análise. Os locais em que tais experiências ocorreram - uma clínica-escola que se desenvolve na universidade e uma instituição médica de reabilitação motora - compõem não apenas o cenário de sua realização, mas têm incidência direta sobre o desenrolar desse trabalho, seja nas dificuldades encontradas, seja nas vias que puderam ser abertas.

No contexto da clínica-escola, apresentamos os seguintes fragmentos de caso, colhidos a partir da experiência de supervisão: "Tenho certeza que um dia vão descobrir o que eu tenho"; "Sei que meu problema é emocional, o médico disse"; “Como me livro disso, doutora?”. São fragmentos de uma análise tornada possível porque foi sustentada pela supervisão e análise pessoal da psicóloga responsável pelo atendimento.

Quando começou a ouvir José, a psicóloga tinha dúvidas quanto a ser possível a análise deste caso. Encaminhado do Hospital Geral para atendimento, tinha história de sucessivas entradas em emergências motivadas por dor abdominal intensa. Isto levou a equipe médica a investigar, durante um longo período de exames clínicos, tomografias e ultrassons, a causa desta condição. Como não havia nada orgânico que a justificasse, recebeu o diagnóstico de doença psicossomática. Já tendo passado por várias especialidades médicas, José dizia ter esperança de encontrar um médico que descobriria sua doença. Queria encontrar na medicina a resposta para seu mal, dificultando a instauração da transferência. Entretanto, José era assíduo nos atendimentos semanais, relatando detalhes das crises e de como fora socorrido às pressas nos hospitais. Por outro lado, podia-se perceber em José a dificuldade de desprender-se da doença, a qual trabalhava em nome da resistência à prática analítica. Este discurso levava a psicóloga a se questionar se não seria melhor dispensá-lo, pois esperava que ele formulasse uma questão endereçada a ela. Como a referência a um saber inconsciente não emergia, a profissional não vislumbrava uma mudança de posição em relação ao saber. A fixação do sujeito ao diagnóstico médico de doença psicossomática levava-a a indagar-se sobre a possibilidade de trabalho analítico. Um primeiro ponto levantado na supervisão referia-se ao diagnóstico de doença psicossomática. Se, para a medicina, as disfunções sem causa orgânica são diagnosticadas como doenças psicossomáticas, para a psicanálise impõe-se precisar a diferença entre sintoma e fenômeno psicossomático na direção da cura. Poderia a dor de José ser inscrita na ordem dos fenômenos psicossomáticos? Esta era uma questão importante a ser respondida, pois o manejo clínico nestes casos comporta algumas particularidades. 
No segundo caso que trazemos à discussão, a experiência de análise ocorreu em uma instituição de reabilitação motora, designada como prestadora de serviços do SUS (Sistema Único de Saúde) para o atendimento interdisciplinar ao paciente portador de deficiências (PPDs). Os pacientes assim designados apresentam quadros de comprometimentos físicos de alta e média complexidade, que demandam várias especialidades de tratamento, como fisioterapia, fonoaudiologia, terapia ocupacional, psicologia e serviço social.

Passemos ao extrato clínico.

A paciente era uma jovem que apresentava uma doença psicossomática, inicialmente diagnosticada como síndrome de Parsonage de Turner. A manifestação de outros sintomas que não correspondiam a este transtorno fez com que, após uma série de exames e idas a especialistas, chegassem ao diagnóstico de Miastenia Gravis. Além dos efeitos debilitantes desta doença, a paciente apresentava outras complicações de saúde, como problemas gástricos, respiratórios e alergias. Havia também reações somáticas como constipações, etc., formando um quadro no qual o seu corpo era palco de uma infinidade de manifestações. Assim, foi encaminhada pelo médico para acompanhamento psicológico, por apresentar uma doença que, segundo ele, estaria relacionada ao aspecto emocional. Deste modo, a paciente chegou ao setor de psicologia à procura de mais um especialista.

Logo as características do seu discurso ficaram evidentes, tais como a aderência ao discurso médico, a fala descritiva e concreta em que aparentemente a angústia não estava presente. Manifestava um “desafetamento”, um descaso pela sua condição física. Não apresentava sinais de abertura à transferência, não formulando uma questão que pudesse endereçar à analista. Esta era colocada como expectadora da descrição de seus tratamentos, que ocorria como se ela estivesse falando de outra pessoa. O seu corpo era entregue, sem questionamentos, a exames que causavam dor. Cometia excessos com o seu corpo, indicando que não conhecia os seus limites.

A instituição onde a paciente foi acompanhada é regida pelo discurso médi$\mathrm{co} /$ pedagógico, e tem como características principais a busca da funcionalidade motora, abrangendo diversas manifestações do corpo, a integração e a inclusão social. Os efeitos desse discurso se fazem sentir com um empuxo normatizador, acompanhado de um franqueamento do corpo, que fica reduzido e identificado a objeto de intervenção da medicina. No entanto, o corpo é a sede de manifestações que ao mesmo tempo escapam a esse saber médico e anunciam que há um sujeito em causa. Neste cenário, a via somática é a privilegiada para as manifestações do sujeito, como tentativa de constituição de uma demanda ao Outro. A resposta médica a esta demanda pode reforçar o tamponamento daquilo que é do inconsciente, através dos procedimentos e técnicas que têm por objetivo exclusivamente a remissão dos sintomas e a readaptação. Deste modo, pode-se 
encobrir alguma notícia sobre o sujeito, especialmente no modo de resposta ao sintoma. Isso não impede, contudo, que se mantenha um gozo localizado no corpo (PITANGA, 2006).

No Setor de Psicologia desta instituição, a psicanálise é o instrumento teórico/clínico utilizado nos atendimentos, na aposta da emergência do sujeito do inconsciente e seus efeitos, na tentativa de um diálogo com o discurso médico. Na sustentação deste trabalho os psicanalistas se deparam com dificuldades comuns encontradas em outros serviços no âmbito público, como no campo da saúde mental, na dicotomia entre a clínica e a política, no entrecruzamento dos discursos médico, psicanalítico e de atenção psicossocial (RINALDI, 2005). Nesse contexto, a grande demanda de resolução de problemas sociais, econômicos e mesmo orgânicos, muitas vezes dificultam a delimitação de uma demanda que pode se considerar como subjetiva.

A instituição em questão, porém, apresenta particularidades que comparecem também no próprio dispositivo de escuta. Destacamos dificuldades muito peculiares encontradas na clínica de uma categoria de pacientes que apresentam os chamados fenômenos psicossomáticos (FPS) — mais precisamente, aqueles que apresentam doenças psicossomáticas que interferem na qualidade de suas vidas, bem como as ameaça, por sua gravidade. Essas dificuldades referem-se a um "desafetamento" no que diz respeito ao que acontece em seus corpos, aonde a instância simbólica parece estar elidida, implicando um aparente abandono de seus corpos à sorte da biologia e dos procedimentos médicos. O discurso dos pacientes reproduz o discurso médico, traduzindo a posição a que estão identificados: de objetos, assujeitados pela lesão que carregam, apontando para um ponto em suas estruturas psíquicas sobre o que não têm condições de significar (PITANGA, 2006).

Ainda que resguardadas as singularidades e as diferenças entre os casos apresentados, alguns elementos se repetem em ambas as histórias. De início, a fixação ao diagnóstico de "doença psicossomática”, que os conduz à busca de especialistas; em seguida, o encaminhamento médico para a psicologia, em virtude de um ponto de opacidade que questiona o saber do médico, que o relaciona a "algum fator emocional". Por fim, a dificuldade que os pacientes apresentam, durante as entrevistas preliminares, de abrir espaços para dialetizações no que diz respeito à doença. Em lugar do sintoma, demonstram uma fixação ao fenômeno psicossomático. Poderíamos até categorizar os FPS como um sintoma, porém não se trata, pelo menos neste momento, de um sintoma no sentido psicanalítico. Ou seja, o sujeito não faz, de início, um estranhamento daquilo de que padece, e, por isso mesmo, não se indaga sobre algo que tocaria o inexplicável, de modo a endereçar uma demanda ao analista. Portanto, não há, nesse momento, aquilo que se entende por condições mínimas para um tra- 
balho analítico. A transferência não se constitui, pois o analista não é colocado na posição de Outro, como suposto saber — pelo contrário, a ele é reservada a posição de espectador.

A instauração do ato analítico só se realiza com a demanda, por parte do analisante, de se desembaraçar de um sintoma. Este, para a psicanálise, é aquilo que o sujeito sabe que tem a ver com ele, mas não sabe o quê. Isso que não sabe, transfere a um sujeito suposto saber. Trata-se de uma divisão em relação ao saber, e o sintoma é o que sustenta a realidade como realidade psíquica. Mas o sintoma, para se constituir como tal, apresenta-se a partir do enlaçamento ao simbólico, sendo designado sintoma por ter adquirido função de significante, algo que só surge na experiência analítica, ganhando valor de enigma para o sujeito e sendo passível de interpretação. Se uma manifestação sintomática não é incluída no registro simbólico, não poderá ser interrogada, permeando o tratamento com particular dificuldade.

Como veremos mais adiante, diferentemente do sintoma, o FPS concerne ao real (LACAN, 1954-55/1985), tendo uma inscrição ilegível, pois está fora da dimensão simbólica. Lacan (1975) fala de um gozo específico nos FPS, assim denominado porque é fixado, fora do simbólico. Por isso, a passagem do gozo ao inconsciente é particularmente difícil nesta clínica. Como fazê-lo diante do discurso da medicina cujo efeito é obturá-lo? Considerando o fato de que outros discursos na prática dos serviços podem subsumir o psicanalítico, nossa experiência nos diz que, para que isso não aconteça, faz-se necessário sustentar o lugar do sujeito. O que impulsiona, então, o analista a questionar se há possibilidade de trabalho analítico nestes casos?

Freud nos advertiu sobre a importância do tratamento de ensaio prévio ao trabalho analítico, ainda que tenha chamado a atenção também para o fato de que essa é uma "recomendação", lembrando a "extraordinária diversidade de constelações psíquicas envolvidas e a plasticidade dos processos mentais” (FREUD, 1913/1976, p.164), que desaconselham qualquer mecanização da técnica. A recomendação é para que o analista esteja ciente de um tempo de espera, necessário para o começo de um trabalho que avança apesar da resistência. Refere-se à importância de deixar o paciente falar e não se explicar nada mais do que o absolutamente necessário para fazê-lo prosseguir. A tarefa do analista é de escuta, atenção flutuante ao que está sendo comunicado, até que algo se defina como uma demanda. Cada paciente traz um caso novo, e de nada vale ao analista acumular o saber que tem sobre outros. As recomendações de Freud são claras para que se considerem as lacunas e limitações próprias deste tempo preliminar, tempo crucial para a instauração 'espontânea' da transferência.

Se as recomendações freudianas indicam ser necessária, por parte do analista, certa dose de paciência para que um trabalho de análise seja possível, nas duas 
situações clínicas apresentadas, as dificuldades do trabalho de escuta apresentaram essa especificidade, ligada à presença dos FPS, que dá características especiais a esse "tempo de espera". Ainda que saibamos que a psicanálise se dá no um a um, temos a tarefa de, amparados na teoria psicanalítica e em nossa prática, construir algo que se possa chamar de uma clínica do paciente psicossomático, fazendo frente a essas especificidades.

Procuramos buscar no ensino de Jacques Lacan elementos que permitam pensar, tanto o que se passa no funcionamento psíquico destes sujeitos, como também encontrar indicações que possam representar vias para o encaminhamento de um trabalho analítico, já que, como dissemos, de início não parecem se constituir as condições mínimas que demarcariam o final das entrevistas preliminares e uma entrada em análise, com a articulação da demanda.

No território médico, a psicossomática é um campo de estudos e de pesquisa que tem por função diminuir a hiância provocada pelo desenvolvimento das especialidades médicas que resultaram em um distanciamento dos fatores que interagem na manutenção da saúde, e daqueles que participam dos fenômenos do adoecimento. A psicossomática trata dos casos em que a relação anatomopatológica não é suficiente para explicar a doença, a sua evolução e até mesmo a sua extinção. São casos que desconcertam os médicos e outros profissionais que eventualmente os acompanham (PITANGA, 2006). Nestes casos estão incluídas as doenças autoimunes, como o Lúpus Eritematoso Sistêmico, cuja particularidade em relação à psicossomática buscamos estabelecer (NICOLAU e MORAES, 2010). As doenças autoimunes são definidas como “doenças de autoagressão, as quais parecem desenvolver certas reações imunes aos constituintes naturais do organismo (self), levando a lesões localizadas ou sistêmicas" (CALDEIRA e SILVA, 1992, p.139).

Com estas indicações vindas do campo da medicina, podemos fazer uma distinção precisa entre os FPS e a conversão histérica com relação ao envolvimento do corpo nas suas manifestações. O primeiro apresenta prejuízo orgânico identificável; no segundo, o prejuízo é funcional. Porém, a distinção mais contundente é que na histeria há uma "relação simbólica” que situa no corpo representações inconscientes recalcadas, como descreveu Freud em vários momentos (FREUD, 1893/1976, p.45).

Para avançar com o questionamento da possibilidade de trabalho analítico com pacientes psicossomáticos, destacamos algumas indicações no ensino de Lacan. Podemos seguir as elaborações lacanianas sobre o campo da psicossomática em três direções, a saber: a dimensão narcísica, a dimensão significante e a dimensão do gozo.

Inicialmente, Lacan abordou o tema da psicossomática do ponto de vista do narcisismo no Seminário, Livro 2 (1954-55). Na aula intitulada "Introdução 
ao Entwurf", trabalhou a relação ao objeto do ponto de vista da pulsão e do narcisismo, dizendo que, para que haja relação ao objeto, é preciso uma relação narcísica entre o eu e o outro. A estruturação do eu se efetua em torno da identificação a uma imagem especular do corpo próprio. É neste ponto que está a linha divisória do narcisismo que delimita o que é do campo da neurose e o que é o campo da psicossomática. Lacan situa deste modo a psicossomática como relacionada ao registro do real. Ele diz:

"Não se trata de uma relação de objeto. Trata-se de uma relação a algo que está sempre no limite de nossas elaborações conceituais, em que se pensa sempre, de que se fala por vezes, e que propriamente falando não podemos apreender e que, no entanto está aí, não se esqueçam disto - estou-lhes falando do simbólico, do imaginário, mas há também o real. As relações psicossomáticas estão no nível do real.” (LACAN, 1954-55/1985, p.125)

Esta ideia sugere que algo do corpo não se rendeu à entrada da linguagem, permanecendo na condição de organismo, sem ser marcado pelo simbólico. A psicossomática, deste modo, pertence a uma área que contorna a estrutura de linguagem, no campo, por trás do narcisismo, do autoerotismo movido pela entropia, ou seja, movido pela pulsão de morte. O corpo é sede de uma erotização de órgãos e de uma escrita particular que não tem a mediação da via simbólica. Os FPS não têm, portanto, a mesma estrutura dos sintomas neuróticos, uma vez que não apresentam uma relação simbólica e não podem ser identificado a uma formação do inconsciente, parecendo-se mais com uma direta inscrição no corpo.

No entanto, os FPS atravessam o trabalho de análise de maneira peculiar, silenciosa e insidiosa, interrogando a psicanálise nas suas bases, exigindo um posicionamento ético do psicanalista. Insistimos neste ponto seguindo o apontamento de Lacan de que psicossomática só tem algum valor para a psicanálise porque mantém uma relação com a lei do desejo. Esta distinção entre FPS e sintoma histérico tem uma consequência importante para o alcance do trabalho analítico, pois eles não são passíveis de decifração e, assim, são inacessíveis à interpretação. Dizem respeito a uma escrita, mas uma escrita ilegível. Assim, chega-se ao ponto no qual o analista faz uma aposta da passagem do fenômeno para algo do alcance da interpretação, o que é sustentado pelo desejo do analista. Podemos entrever aí um primeiro indicativo de direção de trabalho neste caso particular da presença do fenômeno psicossomático.

A dimensão significante está relacionada ao que Lacan trabalhou no Seminário, livro 11 (1964), com o conceito de holófrase, como a gelidificação do par de significantes S1e S2. Neste caso, a psicossomática está incluída como um dos 
efeitos dessa gelidificação, entre a debilidade mental e a psicose. Quando ocorre a holófrase, há um ataque à metáfora subjetiva, não ocorrendo afânise, nem queda do objeto a. A afânise remete à constituição do sujeito, sendo um termo que Lacan retoma de Ernest Jones, ${ }^{1}$ em um sentido mais radical, para descrever o efeito de desaparecimento do sujeito, quando representado de um significante para outro. Nas palavras de Lacan:

“[...] o sujeito aparece primeiro no Outro, no que o primeiro significante, o significante unário, surge no campo do Outro, e no que ele representa o sujeito, para um outro significante tem por efeito a afânise do sujeito. Donde - divisão do sujeito - quando o sujeito aparece em algum lugar como sentido, em outro lugar ele se manifesta como fading, como desaparecimento." (LACAN, 1964/1988, p.207)

A ausência da afânise do sujeito implica que não há intervalo entre S1 e S2 (primeiro par de significantes), ficando estes significantes fundamentais holofraseados. Ele se refere à holófrase como emassamento, gelificação, cristalização, colagem, quando o significante materno ou mestre (S1) não é substituído pelo significante da metáfora paterna (S2), permanecendo ambos colados, aderidos. O efeito causado pela gelidificação dos significantes é a impossibilidade de haver uma dialética entre os significantes que permita o surgimento do sujeito no intervalo entre eles.

Entretanto, na psicossomática, diferentemente do que ocorre no autismo, na debilidade e na psicose, o desejo está preservado "mesmo se não podemos dar conta da função afânise do sujeito” (Lacan, 1964/1998, p.215). Trata-se de um significante colado ao corpo, que não se articula à cadeia significante, ficando holofraseado.

Na "Conferência em Genebra sobre o sintoma” (1975), Lacan indica um caminho para se pensar o FPS ao assinalar que a questão é saber qual é a espécie de gozo que se encontra aí implicado. Lacan afirma que a relação do paciente psicossomático com o corpo é da ordem de uma escrita ilegível que se assemelha a hieróglifos, o que remete a uma forma de configuração do traço unário, que tem como consequência uma fixação de gozo, ou um gozo "congelado" (LACAN, 1975/1998). Isso nos conduz à terceira via de abordagem do campo da psicossomática, o gozo.

Lacan refere-se ao gozo que se encontra no psicossomático, dizendo: “[ [..] se evoquei uma metáfora como a do congelado é porque há efetivamente essa fixação [...] é porque o corpo se deixa levar a escrever algo da ordem do número"

\footnotetext{
${ }^{1}$ Esse termo é introduzido por Ernest Jones em 1927 "para designar o desaparecimento do desejo e o medo desse desaparecimento, tanto no homem quanto na mulher" (ROUDINESCO \& PLON, 1988, p.8).
} 
(1975/1998, p.139). O que é da ordem do número não faz série, mas atua como pura frequência, um sinal unívoco da cifra, contagem do gozo, que aponta para uma possível escrita do real. Esse gozo é denominado específico, pois é fixado, fora do simbólico (NICOLAU, 2008).

Um trabalho analítico possível seria na direção de uma intervenção na economia de gozo que pudesse revelar o gozo específico que há na fixação, produzindo um distanciamento entre o traço e a inscrição corporal, através do trabalho com o inconsciente. É esta a direção indicada pelo ensino de Lacan, já que "o psicossomático é algo que, de todo modo, no seu fundamento, está profundamente arraigado no imaginário” (LACAN, 1975/1998, p.14).

A análise será o trabalho de sair dessa fixação para escrever a própria história, fabricar uma ficção. O que se espera na direção da cura é um tratamento do gozo que possa bordejar o real, dar-lhe um sentido, sentido esse que aponta para um gozo específico, sustentado por um significante indutor, ao qual o sujeito está aprisionado (NICOLAU, 2008).

Seria uma operação no limite do sentido, em direção ao real que não caberia decifrar, uma vez que resta como inacessível, indecifrável. Esta ideia marca o último ensino de Lacan, quando ele opera uma disjunção entre o sujeito do significante e o sujeito do gozo. De um lado, o sujeito do significante funciona como base para uma clínica orientada pela produção do sentido; de outro, o sujeito do gozo veicula um modo de satisfação e um circuito de repetição que estão além da captura de sentido pelo significante. A interpretação visa reduzir os significantes a seu não-senso, apostando não apenas na redução operada pelo trabalho significante, mas numa certa maneira de lidar com este gozo que resta não analisável. É com este resto que o sujeito deverá saber e fazer, como propõe Lacan na década de 1970.

Diante de um sujeito entregue a um gozo mortífero, concentrado em seu corpo, Lacan nos ensina que é preciso considerar uma perda de gozo, indicando a condição do sujeito como falta-a-ser, para que o sujeito exista nas entrelinhas da rede significante. Quando o sujeito está petrificado por sua doença, seu corpo se torna fonte ilimitada de gozo, apontando para um corpo do qual a palavra desertou, não havendo uma escrita legível. Tomado desta maneira, o órgão funciona como sendo de um outro, feito para gozar como se pertencesse a esse outro. Na direção da cura, é este gozo que deve ser reduzido.

A questão do gozo na psicossomática pode ser abordada ainda através da formulação do conceito de Sinthoma desenvolvido por Lacan no Seminário 23 (1975-76). A psicossomática poderia ser uma forma de sinthoma, como um dos Nomes-do-pai, que, na condição de quarto elo no nó borromeano, faz uma suplência na tentativa de uma sutura entre os registros real e o simbólico, como nos indica Jean Guir (1988). 
Voltemos aos fragmentos clínicos para pensar o alcance dessas elaborações.

José conta, em uma sessão, que desmaiou de dor, sendo levado ao hospital. O médico que o atendeu disse que ele não tinha nada, que era coisa de sua cabeça. Ele ficou com raiva do médico e passou a falar dessa raiva, associado ao fato de que não acreditavam nele. Quando criança, os pais desconsideravam as coisas que dizia. Neste instante, aparece o desejo de reconhecimento, que opera nele uma mudança. Passa a indagar sobre a causa psicológica de sua dor, tentando localizá-la nos acontecimentos de sua vida, demandando à psicóloga que respondesse - já que seu problema é emocional, ela saberia localizar a causa. Esta, que antes respondia e explicava, passou ao silêncio. Parece que a escuta sustentada pela supervisão permitiu que, ao não responder, fosse possível fazer furo na verdade estabelecida pelo discurso médico, para que o sujeito tivesse acesso a sua verdade.

José começa a fazer associação das dores com os conflitos familiares. Neste tempo de análise, as dores diminuíram. Começou a apresentar erupções pelo corpo e psoríase, que associava com aborrecimentos em casa, pedindo uma resposta para o deslocamento de sintomas: "porque isso agora? (...) Será que eu ainda vou apresentar outro sintoma?". Várias associações foram feitas, e em suas perguntas algo já se apresentava como resposta. Lembrou-se da época em que era criança e que nunca ficava doente, e que só o irmão que, ao adoecer, era prontamente medicado: "quando era comigo, minha mãe dizia que não era nada, mas meu irmão tinha sempre uma atenção especial".

Dores abdominais, erupções na pele, psoríase, não é nada, atenção especial ao irmão doente, falta de reconhecimento da mãe, surgimento de sucessivos sintomas no corpo. O que mais faltaria para essa cadeia ser um mito neurótico? A narrativa dispõe de todos os elementos, mas não há qualquer associação ou construção com estrutura de mito individual. Existia uma amarração que parecia fazer cadeia, mas, estranhamente, não remetia um significante a outro. A função significante, tal como a conhecemos, por representar o sujeito para outro significante, não se realizava ali. Quando surgia um novo sintoma, ele o apresentava como descolado dos demais. Os elementos que poderiam construir o sujeito em seu mito eram narrados com a certeza do ineditismo e não associáveis entre si. Cada elemento era um.

Assim, embora a dor que levou José a procurar ajuda aponte para a conversão histérica, o fato de não fazer série levou-nos a pensar em um modo de fixação do significante semelhante ao que ocorre na psicossomática, em que o significante fixado permanece como uma escrita hieroglífica, carecendo de uma dialetização simbólica. Sua dor não remetia a nenhum outro significante, sem estabelecer, portanto, uma cadeia associativa. O manejo, neste caso, não poderia contar com a existência da função de afânise do sujeito. Ou seja, o sujeito não estava ali in- 
teressado enquanto afânise — por isso, o manejo possível era tentar encontrar o desejo sem contar com a afânise.

Pensamos que ao responder com o silêncio, naquele momento preciso, instalou-se um ponto de partida em sua análise. Tratando-se de um sujeito aderido ao imaginário, a aposta é operar do lado do significado, mas com a redução de sentido. Se, de um lado, ele continua a esperar uma resposta que vem do outro, passa também a supor um saber em si para além do orgânico. Vimos a chance de este sujeito se afanisar, abrindo a possibilidade de ser representado de um significante a outro. A consequência dessa operação é a perda de gozo que será inscrita no inconsciente, abrindo a condição para a aparição do desejo. Se o tratamento depende da instauração da transferência, esta parecia ter início. A psicóloga, ao sustentar a escuta não mais pela ambição terapêutica de cura e sim pelo desejo do analista, opera em continuidade ao desejo do paciente. O desejo do analista é o único que sustenta o ato e torna possível uma mudança de posição do sujeito em relação ao saber. Às vezes, o que sustenta é o desejo do supervisor. Esta é uma questão a ser discutida em outro trabalho.

No caso da outra paciente, a insistência da psicanalista que a atendia em sustentar a sua escuta permitiu que algo de novo pudesse surgir. De início, a sua história de vida foi relatada quase por acaso, quando, aos poucos, pôde-se verificar alguns elementos que se constituíram como fundamentais. A nomeação dada a ela pela mãe — "Maria das Dores" — quando era ainda pequena, e a própria história de seu nome verdadeiro, que foi uma homenagem à avó doente. Havia ainda uma identificação ao pai doente, completando uma série de significantes que a identificava: “doente”, “doença”, “dor”. Não via o seu nome como próprio, não se apropriava dele, tinha a sensação que portava o nome da avó. O mesmo ocorria com o seu corpo.

$\mathrm{Na}$ insistência, durante alguns anos, deste trabalho de oferta de uma escuta, ficou clara uma sequência de acontecimentos que a paciente não verbalizava, mas aos quais reagia com uma resposta somática. A hipótese estrutural com que se trabalhava inicialmente era de neurose histérica, o que sustentava este trabalho como uma aposta. Mas havia um ponto na sua estrutura subjetiva que se apresentava de forma enigmática. As manifestações eram respostas a eventos da sua vida através de uma escrita corporal, onde o simbólico parecia não ter lugar. As pontuações da analista eram realizadas, mas pareciam exercer pouco efeito.

O relato de um sonho trazido pela paciente demarcou de maneira decisiva um deslocamento de sua posição subjetiva. Chegou para a sessão abatida dizendo que não dormiu bem à noite por causa de um sonho que precisava contar. Sonhou que assistia ao seu próprio corpo sendo autopsiado. Olhava o médico examinar seu corpo inerte. As associações que se seguiram a este relato levaram a um redimensionamento do trabalhado analítico, pois este sonho lhe causou 
grande impacto, o que fez com que ela fosse apresentada à experiência de angústia. A partir deste ponto, a transferência ficou mais evidente, quando pôde também remeter às intervenções feitas pela analista no percurso de trabalho de análise, especialmente ao que era apontado sobre sua relação com o seu corpo, que antes estava entregue a própria sorte. Passou a ter medo da morte e a se preocupar com seu destino, fazendo questionamentos sobre aquilo que manifestava no corpo, tomada que estava pelo horror. A doença e as suas manifestações assumiram a partir daí um novo estatuto, que podemos designar como de sintoma no sentido analítico, movido pela angústia.

A passagem efetuada, do fenômeno psicossomático ao sintoma, apontou, neste caso, para uma possibilidade de alcance do trabalho analítico que, em determinadas condições pode atingir o limite do encontro da linguagem com o corpo. Neste caso, através do sonho, significantes holofraseados, os quais faziam uma direta inscrição, puderam ser "desfixados", postos ao trabalho de análise. Deste modo, fez-se uma entrada da operação simbólica, colocando em curso um trabalho psíquico. Abriu-se assim uma possibilidade de desaglutinar o gozo fixado no corpo na direção da produção de sentido.

Lacan indicou que no trabalho da análise é preciso fazer uma sutura, um cerzido entre o imaginário e o simbólico com o saber inconsciente. Ele diz: "tudo isso para obter um sentido. O que é o objeto da resposta do analista ao relatado pelo analisando, ao longo do seu sintoma" (LACAN, 1975-76/2007, p.70-71). E prosseguiu dizendo que quando acontece essa emenda entre o imaginário e o simbólico, ocorre também outra, entre o sintoma e o real, em que se aloca o gozo parasitário. A tarefa do analista seria, assim, possibilitar que o analisante possa fazer emendas e desaglutinar o gozo fixado no corpo, para a produção de sentido.

Os dois fragmentos de casos discutidos, resguardadas as suas singularidades, permitiram que destacássemos alguns pontos em comum. Em ambos, a hipótese diagnóstica sustentada pelas analistas e no trabalho de supervisão convergiu para a neurose histérica, estrutura que se apresentou, contudo, atravessada por fenômenos psicossomáticos. Esse atravessamento deu-lhe características específicas que encobriram o sintoma, representante do desejo do sujeito, dificultando a constituição de uma demanda de análise. Foi a insistência na oferta de escuta do inconsciente, sustentada pelo desejo do analista e pela ética da psicanálise, que possibilitou a entrada em análise, a partir da instalação da transferência. Esse trabalho, como vimos, possibilitou a desaglutinação do gozo fixado no corpo e a dialetização da cadeia significante, fazendo a passagem do fenômeno psicossomático, que dominava a cena, ao sintoma, quando o sujeito pôde enfim se reconhecer. 


\title{
REFERÊNCIAS
}

CALDEIRA, G. SILVA, A., F. (1992) Alexitimia e pensamento operatório. A questão do afeto na psicossomática. Psicossomática hoje. Porto Alegre: Artes Médicas.

FREUD, S. (1976) Edição standard brasileira das obras psicológicas completas de Sigmund Freud. Rio de Janeiro: Imago.

(1893/1976) “Estudos sobre histeria: sobre o mecanismo psíquico dos fenômenos histéricos: comunicação preliminar”, v.II, p.45.

(1913/1976) "Sobre o início do tratamento (Novas recomendações sobre a técnica da Psicanálise I)”, v.XII, p.164.

GUIR, J. (1988) A psicossomática na clínica lacaniana. Rio de Janeiro: Jorge Zahar Editor.

LACAN, J. (1954-55/1985) O Seminário, livro 2: O eu na teoria de Freud e na técnica da psicanálise. Rio de Janeiro: Jorge Zahar.

(1964/1998) O Seminário, livro 11: Os quatro conceitos fundamentais da psicanálise. Rio de Janeiro: Jorge. Zahar Editor.

. (1966/2010) O lugar da psicanálise na medicina. Opção lacaniana, n.32.

. (1975) Conferência in Ginebra sobre el sintoma. Intervenciones y textos. Buenos Aires: Manantial.

. (1975-76/2007) O Seminário, livro 23: o sinthoma. Rio de Janeiro: Jorge Zahar Editor.

NICOLAU, R. (2008) A psicossomática e a escrita do real. Mal-Estar e Subjetividade v.8, n.4, p.959-990. Fortaleza: Universidade de Fortaleza. e MORAES, J., L. (2010) in PIMENTEL, A., LEMOS, F., SOUZA, M, E NICOLAU, R. (Org.) Itinerários de pesquisa em psicologia. Belém: Amazônia Editora.

PITANGA, C. (2006). Psicanálise e psicossomática: por uma análise possível. Dissertação de mestrado do Programa de Pós-graduação em Psicanálise da Universidade do Estado do Rio de Janeiro. Disponível em www. pgpsa.uerj.br.

RINALDI, D. (2005). Clínica e política: a direção do tratamento psicanalítico no campo da saúde mental. Psicanálise, clínica e instituição. Rio de Janeiro: Rio Ambiciosos.

ROUDINESCO, E. \& PLON, M. (1998) Dicionário de psicanálise, Rio de Janeiro: Jorge Zahar Editor.

\author{
Doris Rinaldi \\ doris_rinaldi@yahoo.com.br; doris@uerj.br \\ Roseane Freitas Nicolau \\ Rf-nicolau@uol.com.br \\ Claudia Escórcio Gurgel do Amaral Pitanga \\ pitangaclaudia@terra.com.br
}

